\title{
The Role of Achtung in Kant's Moral Theory
}

\author{
SHARON E. SYTSMA
}

Northern Illinois University

In this paper, I would like to pursue a comment made by Thomas Nagel in his book, The Possibility of Allruism, concerning a possible problem with consistency in Kant's theory of moral motivation. 1 In general, Nagel applauds Kant's theory of moral motivation. He thinks that in the history of Ethics Kant has done the most to present a description of moral motivation which is not dependent on any desires or feelings prior to or outside of the recognition of a moral obligation itself. Kant attempts to "put ethical principles themselves at the absolute source of our moral conduct" (PA, 11); he denies that any motivational influence is "already present among the conditions of any moral requirement" (PA, 13); and he insists that "there are reasons for actions which are specifically moral" (PA, 13). All this meets with Nagel's approval, and Nagel himself attempts to provide a "defense" for such an "internalist" theory. 2 What is troubling for Nagel is that Kant also allows for the phenomenon of Achtung, or moral feeling in the form of respect for the moral law. Nagel's comment is the following: "It seems possible that Kant's postulation of moral interest as the motivating impulse for phenomenal moral behavior compromised the effort [to establish moral reasons as themselves the independent source of moral motivation]" (PA, 11).

Nagel's worry is shared by others. Mark Timmons, for instance, argues that Kant's positing of a mysterious, a priori feeling (Achtung) was indeed superfluous and merely symptomatic of his unreflective Aristotelian heritage, and that if Kant could have liberated himself from that influence, he would have provided an account of morality similar to Nagel's. ${ }^{3}$ Timmons thus suggests that Kant did in fact "compromise the effort" to give an account of ethics which shows that reason itself is the source of moral motivation. E. J. Bond, who rejects Nagel's rational internalism, states: "But even Kant recognized that some motivational factor was necessary to

1 Thomas Nagel, The Possibility of Altruism (Princeton: Princeton University Press, 1970). Hereafter, referred to in the text as PA.

2 Nagel defines internalism as the view that moral motivation is "tied to the truth, or meaning, of ethical propositions themselves." Weak internalist theories (such as emotivism) tie motivation to the menning of ethical propositions; Nagel seeks to develop a stronger internalist theory which ties the motivation to their "Iruth"--meaning that once one recognizes a moral ubligation, one is motivated by it, independently of whatever wants, desires or feelings the agent might be experiencing (P'A, 7-8).

3 Mark Timmons, "Kant and the Possibility of Moral Motivation," Southern fournal of Philosophy 23 No. 3 (1985): 377-398. 
account for being moved to act on moral grounds, beyond the mere recognition of the law, and he called that "reverence" or "respect" for the law."4

The problem, then, is this: Does Kant hold that the recognition of a moral obligation itself provides the motivation to act morally, or does he believe that in addition to this recognition, moral feeling is required as a motivational impetus for moral action? Is it possible that reason could give a moral command and yet fail to motivate, because of the lack of the experience of moral feeling? More to the point: Is reason independently motivating or is it not?

These questions demand a clarification of the role of moral feeling in Kant's theory of moral motivation. Admittedly, as I will show, there are grounds for the confusion in the interpretation of its role in Kant. However, I will argue that Kant's doctrine on moral feeling can be interpreted so that it in no way contradicts nor "compromises" his main tenet that reason can independently motivate moral action. Since, for Nagel, (rational) internalism guarantees motivation upon the recognition of a moral obligation, I argue that Kant can be interpreted in such a way as to leave his rational internalism uncompromised.

In his chapter on the "Incentives of Pure Practical Reason" in the Second Critique, Kant gives his most concentrated discussion of the phenomenon of moral feeling. Kant begins this section with his oft-repeated claim that actions have moral worth only when the will is determined by the moral law itself, independently of any other motivating influence. Actions which are merely done in conformity with the moral law, but not for the sake of the moral law, have "legality" but not "morality"; they are "morally good in letter but not in spirit (in intention)" (CPrR, p. 74; 75n). The only incentive to truly "moral" actions "can never be anything other than the moral law" (CPrR, 74). If this is true, then why does Kant go on to speak of moral feeling, and how are we to understand its role (if it has one) in moral motivation?

The discussion of moral feeling is undertaken, not in order to explain how the moral law "determines the will," that is, how it functions as a motivating influence. For the problem of how the moral law motivates is the problem of freedom, which cannot be explained through reason. So Kant says that "nothing remains" but to explain carefully "in what way the moral law becomes an incentive" (CPrR, 75). That is, nothing remains but to describe the "subjective effects" of the motivating influence of the moral law on the human mind. By "subjective effects" Kant does not mean effects which vary between individuals according to their respective desires, but simply effects of the objective moral law which are experienced on the part of the human subject because of their human constitution. The discussion of moral feeling is presiented as a phenomenological description of the manner human moral agents are affected by the moral law.

4 E. J. Bond, Reason and Value (Cambridge: Cambridge University Press, 1983) 11. 
The effects of the moral law on the human mind are ubiquitously experienced, but they can also be known a priori. They can be known a priori given the analysis of human beings as having both a sensuous nature determining inclinations, and a rational nature, which issues moral commands. To say that these effects can be known a priori means that these subjective effects are nectssary. The necessary, a priori effects of the moral law on the human mind are both positive and negative.

In a human being, the commands of reason will necessarily conflict (at some time or other) with the inclinations of its sensuous nature. The freedom to choose to act morally independently of inclinations, or even contrary to inclinations must result in pain. Pain is the "thwarting" of our inclinations. Our selfish concerns are "humiliated" in the face of the moral law; the moral law "checks" our self-conceit, preventing it from fully determining our actions (CPrR, 74; 75). Kant calls the experience of humiliation and the "striking-down" of self-love and conceit the "negative subjective effects" of the incentive of the moral law. These negative effects are pathological in nature, meaning that they are derived from our sensuous nature.

The "positive subjective effect" of the moral law is respect for the moral law. Moral feeling can only be respect for moral law as dictated by reason. It can also be known a priori, for the moral law can humiliate only if it exists as an object of respect. While Kant speaks of the feeling of respect as being "awakened" by the negative effects of pain, he also presents the feelings of pain and the feeling of respect as simultaneous, both sides of the same coin (CPrR, 77; 78). Even if the feeling of pain temporally precedes the feeling of respect, the feeling of respect is primary in the sense that there can be no painful humiliation without an object of respect. Kant stipulates that this feeling of respect does not have an "empirical origin," but rather is produced entirely by an "intellectual cause" (CPrR, 76). He states: "This particular feeling cannot be said to be pathologically effected; rather, it is practically effected." With this feeling of respect, we become aware of our autonomy, or of our "supersensuous" existence--in short, we become aware of our intrinsic worth. We become aware of our "supersensuous" nature in the consciousness of our independence from natural influences and of our freedom to act according to universal laws which are self-imposed. This is the consciousness of our distinctive natures as rational beings. It is the consciousness of the sublimity of our natures (CPrR, 91). Kant goes as far as to allow a sense of pleasure in the overcoming of our inclinations in the fulfillment of our duty. Since we are sensual beings, he says that it must be possible for the moral law to exercise itself in this way. 5

The necessary effects of the moral law on the human mind do not apply to the Divine will. In fact, Kant denies that the moral law is an incentive for

5 Immanuel Kant, Foumdations of the Melaphysics of Morals, trans., Lewis White Beck (Indianapolis: The Bobbs-Merrill Company, 1959) 77. (Hereafter, referred to in the text as F). 
the Divine will (CPrR, 74). The moral law is an incentive only for beings for whom reason does not automatically and conclusively determine the will. The Divine or holy will experiences no negative effects of pain or humiliation because it has no sensuous nature conflicting with reason. Reason would be motivating for the holy will without hindrance and without pain. Neither does it experience a feeling of respect for the moral law. The feeling of respect, while caused by pure practical reason, requires a dual (sensuous) nature.

The most significant way in which Kant's concept of moral feeling differs from that of his predecessor's is that it is rationally induced. The feeling of respect for the moral law, while requiring a sensuous nature, is caused by the rational recognition of a moral obligation. It is "produced solely by reason" (CPrR, 79). Kant has "redefined" the whole concept of moral feeling by, in his mind, correcting for the errors of other moral theorists.

Let's turn now to the suggestion that Kant's inclusion of a discussion of moral feeling compromises his rational internalism by contradicting the claim that pure practical reason can, by itself, motivate us to act morally. Suppose we interpret Kant as Nagel, Timmons, and Bond have done, as saying that it is the respect for the moral law, rather than reason itself, which motivates moral action.

The interpretation jars with some claims made by Kant to the contrary. Properly speaking, Kant seems to say, it is not respect which motivates moral action; it is rather reason in the form of the moral law which motivates. He states: "the moral incentive of the human will, can never be anything other than the moral law: (CPrR, 74). He explicitly denies this role to respect: "Thus respect for the law is not the incentive to morality" (CPrR, 78). Kant calls the pure moral law the only "genuine incentive" (CI'rR, 91).6 He speaks of the law as determining the will directly (CPrR, 81). These claims are consistent with those made in his earlier Foundations of the Metaphysics of Morals, where Kant speaks of the "immedtinte determination of the will by the [moral] law" and where he says that the influence of the moral law is "by way of reason alone" (F, 19;28).

However, the matter is not settled so easily, as other passages seem to cast moral feeling as a moral motivator. Kant also refers to respect for the pure moral law (which is moral feeling) as the "sole and undoulfed moral incentive" (CPrR, 81). Further, he does speak of respect for the moral law "promoting" the influence of the moral law, and of the removing of the

6 Note that the reference to the moral law as an incentive diverges from Kant's language in the Fommtations. There, incentives are thought of as being determined by purely subjective concerns: "The subjective ground of desire" is the incentive, while the objective ground of volition is the motive" $(1 ;, 45)$. In the Second Critique, Kant allows that objective grounds can also serve as incentives. See Lewis White Beck, $A$ Comminentury on Kant's "Crilipur of Practical Reason" (Chicago, University of Chicago Press, 1960) 216. 
obstacles of inclination in humiliation (through respect) as a "positive assistance" to the causality of the moral law (CPrR, 78).

If Kant is not himself confused about the role of moral feeling in moral motivation, it must certainly be admitted that his presentation of its role is confused. I do not believe that Kant is fundamentally confused, even though on one page he claims that it is the moral law which is the incentive to morality, and on the next, respect for the moral law. The key passage for the resiolution of this difficulty is the continuation of one previously quoted: "Thus respect for the law is not the incentive to morality; it is morality itself, regarded subjectively as an incentive" (CPrR, 78). The recognition of the moral law in a categorical command is the incentive to morality, but the incentive to morality is experienced by the human subject as respect for the law. To interpret Kant as saying that it is respect for the moral law, rather than the moral law itself, which motivates, is to fail to understand the close connection between the two. Moral feeling (respect) issues from no other source than the moral law. Using Kantian language, while the moral law is the "formal determining ground of action through pure practical reason," the moral law is also a "subjective determining ground of action" and appears, in a being with both a rational and a sensual nature, as respect for the moral law. There is no problem or inconsistency in thinking of respect for the moral law as the moral incentive, as long as one remembers that respect is "produced solely by reason" (CPrR, 79). The feeling of respect, for Kant, is the result of the already motivating power of reason. It refers to the way we experience the moral law as motivating. The feeling of respect is, as it were, the cpiphenomenon of moral motivation.?

When Kant speaks of respect for the moral law as the "sole and undoubted moral incentive" he is stressing (going back to the idea introduced at the beginning of the section on the Incentives) that actions which have moral worth are done out of respect for the moral law, and not because of any other motivating influence. Actions motivated by selfinterest or even sympathy are not, for him, truly moral actions. Since respect is a "singular" or unique feeling, being pure, nonsensuous, issuing only from reason, we may refer $t o$ respect as the moral incentive.

Kant's "rational internalism" is not compromised because Kant never allows that respect for the moral law or moral feeling, rather than reason, motivates moral action. Nor does he allow that we can be cognizant of a moral ubligation and fail to experience respect. Respect can be regarded as an incentive, only because it issues from the dictates of reason in moral law. Since the positive and negative effects of the moral law are necessary (they can be known apriori) there is nothing contingent about the motivating influence of reason. ${ }^{8}$ Therefore, moral motivation is "guaranteed" by the recognition of a moral command. Kant neither allows for the recognition of

7 This term was suggested to me by an anonymous reader.

${ }^{8}$ Whether or not the moral action is accomplished is, however, a contingent matter. 
a moral command without the response of respect, nor the phenomenon of moral feeling without the issuance of a moral command. Moral feeling is not thought of as the basis of, or requirement for, moral commands. Kant states: "no kind of feeling; [even] under the name of a practical or moral feeling, may be assumed as prior to the moral law and as its basis" (CPrR, 77). So, like Nagel, Kant is giving an analysis of moral motivation such that there are "specifically moral" reasons for action; such that morality is not derived from or dependent on feelings; and such that moral principles are the "absolute source" of moral conduct. What is at issue in Nagel's internalism is that moral commands motivate unconditionally, without any dependence on a moral agent's wants, desires, or feelings, and that ethical principles are underived. Categorical commands are not derived from moral feeling, but visa versa. We should not even think of respect as an "intermediary" motivator, such that first the moral law causes respect, and then respect causes the morally appropriate action, by "determining the will." This interpretation would contradict Kant's stipulation that the moral law determines the will "immediately."

In conclusion, Kant never retracts his claim that recognition through reason of a moral obligation provides all the motivation required to act morally. For him, no additional motivational factor is required. Bond is mistaken in interpreting him as suggesting that "some motivational factor beyond the recognition of the law" is required to explain moral behavior. Kant only says that, given a human being, the efficacy of reason is necessarily experienced in the moral feeling of respect. Reason can "independently" motivate moral activity in the sense that it does not depend on any prior influence. Hence, Kant's internalism is left uncompromised.

Kant obviously must have felt that his ethical works would have been incomplete without a discussion of the moral feeling of respect, since he introduces the notion in his Foundations and develops the notion so extensively in the more mature Second Critique. The discussion would not, however, have been incomplete in the sense that without moral feeling there would be no incentive for morality; but only in the sense that its treatment of the psychology of morality would have been incomplete. There would have been no account of the subjective effects of the already motivating influence of reason in the form of the moral law. Kant's ethical works should not be faulted for including the discussion of the moral feeling of respect, for its inclusion adds to the richness of the account and coheres with important elements of our moral experience. 